NBER WORKING PAPER SERIES

\title{
NONTRADED GOODS, NONTRADED \\ FACTORS, AND INTERNATIONAL NON-DIVERSIFICATION
}

\author{
Marianne Baxter \\ Urban J. Jermann \\ Robert G. King
}

Working Paper No. 5175

\section{NATIONAL BUREAU OF ECONOMIC RESEARCH 1050 Massachusetts Avenue \\ Cambridge, MA 02138 \\ July 1995}

The authors are grateful for comments and suggestions from Enrique Mendoza, Maurice Obstfeld, Enrique Sentana, participants in the conference on "International Stock Returns and Business Cycles" hosted by the CEPR, London, June 1994, and seminar participants at the University of Chicago, Wharton, New York University, and the 1994 NBER Summer Institute. All remaining errors are our own responsibility. This paper is part of NBER's research program in International Finance and Macroeconomics. Any opinions expressed are those of the authors and not those of the National Bureau of Economic Research.

(C) 1995 by Marianne Baxter, Urban J. Jermann, and Robert G. King. All rights reserved. Short sections of text, not to exceed two paragraphs, may be quoted without explicit permission provided that full credit, including $\odot$ notice, is given to the source. 


\title{
NONTRADED GOODS, NONTRADED \\ FACTORS, AND INTERNATIONAL NON-DIVERSIFICATION
}

\begin{abstract}
Can the presence of nontraded consumption goods explain the high degree of "home bias" displayed by investor portfolios? We find that the answer is no, so long as individuals have access to free international trade in financial assets. In particular, it is never optimal to exhibit home bias with respect to domestic traded-good equities. By contrast, an optimal portfolio may exhibit substantial home bias with respect to nontraded-good equities, although this result requires a very low degree of substitution between traded and nontraded goods in the utility function. Further, our analysis uncovers a second puzzle: the composition of investors' portfolios appears to be strongly at variance with the predictions of the model that incorporates nontraded goods.
\end{abstract}

Marianne Baxter

Department of Economics

Rouss Hall

University of Virginia

Charlottesville, VA 22903

and NBER

Robert G. King

Department of Economics

Rouss Hall

University of Virginia

Charlottesville, VA 22903

and NBER
Urban J. Jermann

Department of Finance

Wharton School

University of Pennsylvania

Philadelphia, PA 19104 


\section{Introduction}

A basic lesson from finance is that it is optimal to diversify one's portfolio. It is consequently surprising that there is substantial "home bias" in investor's portfolios, that is: investors hold a disproportionate share of their portfolios in domestic assets. Many researchers have suggested that the explanation for home bias is related to the fact that a large fraction of consumption goods are not traded internationally. The idea is that domestic consumers must purchase the domestic nontraded goods, so it is desirable for them to hold a lot of the domestic nontraded good equity, which has high payouts when the output of the nontraded good industry is high. However, we will show that the presence of nontraded goods cannot resolve the home bias puzzle in a world with frictionless trade in financial assets. ${ }^{1}$

Our framework is a multi-country general equilibrium model. Individuals in each country value a traded and a nontraded consumption good, which enter nonseparably in the individual's utility function. Endowments of both types of goods are stochastic. While the traded good may be transported costlessly across countries, individuals must consume their entire endowment of the nontraded good. Frictionless trade in financial assets means that individuals in all countries are free to trade equities representing claims to both traded goods and nontraded goods.

We will take an indirect route to characterizing optimal portfolio holdings in this setting. We begin by characterizing optimal consumption allocations, and then specify portfolio holdings that could support these optimal allocations in a decentralized market setting. This analysis indicates that there is no presumption of home bias implied by this analysis. In fact, our analysis uncovers a second puzzle: the composition of investors' actual portfolios is strongly at variance with the our model's predictions for optimal portfolios.

Section 2 characterizes optimal consumption allocations for each country in the world economy. Because there is only one traded good, the problem amounts to specifying the optimal amount of the traded good that each country should consume, conditional on its endowment of the nontraded good. If the traded and nontraded goods are complements in consumption, it is optimal to allocate more of the traded good to countries with high endowments of the nontraded good. In general equilibrium, however, the world resource constraint for the traded good means that, even if all countries receive a relatively high endowment of the nontraded good, not all countries can have relatively high consumption of the traded good. Rather, a country will receive a relatively high allocation of the traded good only if its endowment of the nontraded good is high relative to the world average endowment of the nontraded good. Specifically, a country's optimal allocation of the traded good depends only on three factors: the world endowment of the traded good; the world endowment of

\footnotetext{
${ }^{1}$ The initial investigations by Krugman (1981), Stulz (1983), and Branson and Henderson(1985) were followed by the contributions of Eldor, Pines, and Schwartz (1988), Stockman and Dellas (1989), Tesar $(1993,1994)$, and Pesenti and van Wincoop (1994).
} 
the nontraded good; and the country's individual endowment of the nontraded good. This finding is very suggestive of portfolio strategies that can support the optimum.

Section 3 describes how to find portfolio holdings that can support the optimal allocations in a decentralized economy. By doing this, we are exploiting the fact that the optimum derived in section 2 can be supported as a competitive equilibrium with appropriate allocations of wealth, and when the planner's shadow prices are reinterpreted as equilibrium prices in competitive markets. As noted above, the optimal allocations depend on three factors. If individuals could trade claims on these three variables and if the shocks are small, these "basic securities" can be used to construct a portfolio that would pay individuals just enough to purchase their optimal consumption bundle. However, assets traded on the organized exchanges have payouts denominated in units of a common numeraire-dollars, for example. In this setting, a claim on the output of a particular industry has a payoff that depends both on the realization of the endowment process for that industry, but also depends on the realization of the relative price of that industry's output in terms of the numeraire. We discuss how to construct and value "market" securities that pay off in units of a common numeraire, which we take to be the traded good. This section also discusses how to construct the necessary "basic securities" as linear combinations of "market securities."

Section 4 considers a special case in which all countries in the world are identical ex ante, although they will differ in the stochastic endowments of the traded and nontraded goods. This special case is useful in developing our intuition about the important features of optimal portfolio choice. This section also describes the relation between our results and those obtained in the earlier literature. Section 5 sets out a simple production model and explores how the supporting portfolio changes in the presence of risk associated with nontraded human capital; Section 6 concludes.

\section{Optimal allocations}

This section develops a multi-country general equilibrium model that we will use to study the determinants of optimal portfolio choice in the presence of nontraded consumption goods. This section begins this analysis by characterizing optimal allocations of traded and nontraded goods; the next section shows how to structure financial portfolios to support these optimal allocations.

With nontraded goods, Pareto optimal allocations concern the international distribution only of traded goods, with the quantity of nontraded goods acting essentially as a shift in preferences. In this section, we characterize Pareto optimal allocations of a single traded good, $\mathrm{X}$, across $J$ countries indexed by $j=1,2, \ldots, J$. These countries have differing endowments of a single nontraded good.

Within each country, the tradable and nontradable consumption goods arrive each period as non-produced endowments. The endowment of the traded good in country $j$ is $\xi_{j}$ and the endowment of the nontraded good in country $j$ is denoted by $\zeta_{j}$. 
Individuals value consumption of both the tradable and nontradable goods; we let $x_{j}$ denote country i's consumption of the tradable good, and let $z_{j}$ denote country i's consumption of the nontradable good.

Pareto optimal allocations are determined by maximizing a weighted sum of individual country utilities $v\left(x_{j}, z_{j}\right)$; letting $\omega_{j}$ denote the weight given to country $j$ with $\sum_{j=1}^{J} \omega_{j}=1$, this weighted sum is given by:

$$
\sum_{j=1}^{J} \omega_{j} v\left(x_{j}, z_{j}\right) .
$$

The resource constraint for allocations of the traded good is:

$$
\sum_{j=1}^{J} \pi_{j} x_{j}=\sum_{j=1}^{J} \pi_{j} \xi_{j} \equiv X
$$

where $X$ is the world endowment of the traded good. The resource weights $\pi_{j}$ allow countries to vary in terms of economic size.

The first-order conditions describing optimal allocations are

$$
\omega_{j} \frac{\partial v\left(x_{j}, z_{j}\right)}{\partial x_{j}}=\lambda \pi_{j}, \quad j=1,2, \ldots, J
$$

together with the resource constraint, (1). These equations imply that optimal allocations are generally of the form

$$
x_{j}=\Psi_{j}\left(X,\left\{z_{j}\right\}_{j=1}^{J},\left\{\pi_{j}\right\}_{j=1}^{J},\left\{\omega_{j}\right\}_{j=1}^{J}\right) .
$$

In particular, optimal allocations depend on the world quantities of the traded good and on all of the individual country quantities of nontraded goods. To learn about the nature of this dependence, it is useful to adopt the following two-step strategy. First, the efficiency condition (2) implies that

$$
x_{j}=\psi\left(\lambda, z_{j} ; \frac{\omega_{j}}{\pi_{j}}\right)
$$

i.e., country $j$ 's allocation of the traded good depends only on $\lambda$ and $z_{j}$, given the country-specific parameters $\omega_{j}$ and $\pi_{j}$. Second, given (3), the equilibrium value of $\lambda$ is determined by world market-clearing for the traded good:

$$
\sum_{j=1}^{J} \pi_{j} \psi\left(\lambda, z_{j} ; \frac{\omega_{j}}{\pi_{j}}\right)=X
$$

This two-stage process has the additional benefit that we explicitly solve for the behavior of $\lambda$, which is the world shadow price of an additional unit of the traded good. This shadow price is important in our subsequent analysis of market equilibrium. 


\subsection{Restrictions on preferences}

To characterize the optimum in detail and to interpret it, we assume that the utility function is specialized to the following:

$$
v(x, z)=(1-\sigma)^{-1} \Phi(x, z)^{1-\sigma}
$$

where the aggregator function $\Phi$ is homogeneous of degree one in $x$ and $z$.

In this specification, the parameter $\sigma$ is interpretable as relative risk aversion with respect to the composite good $c=\Phi(x, z)$. Further, it is also interpretable as the reciprocal of the elasticity of substitution across time or across states of nature.

Since the aggregator $\Phi$ is homogeneous of degree one, it has two properties that we use repeatedly below. First, we may define $\phi(x / z) \equiv \Phi((x / z), 1)$. Then momentary utility can be expressed as:

$$
v(x, z)=\frac{1}{1-\sigma} z^{1-\sigma} \phi(x / z)^{1-\sigma} .
$$

Second, the local behavior of this function can be approximated by a constantelasticity-of-substitution function. The marginal rate of substitution between $x$ and $z$ is $m=[\partial \Phi / \partial x] /[\partial \Phi / \partial z]$, and its elasticity with respect to $(x / z)$, which we denote by $-\mu$, is given by

$$
-\mu \frac{d(x / z)}{(x / z)}=\frac{d m}{m} .
$$

Third, when goods are allocated optimally, the shadow relative price of the nontraded good in terms of the traded good is given by

$$
p \equiv \frac{1}{m},
$$

so that

$$
\frac{d p}{p}=\mu \frac{d(x / z)}{(x / z)} .
$$

That is, increases in $x$ raise the relative price of $z$ and increases in $z$ reduce the price of $z$. The elasticity of substitution between $x$ and $z$ is then given by:

$$
\frac{\frac{d(x / z)}{(x / 2)}}{\frac{d p}{p}}=\frac{1}{\mu} .
$$

Finally, the shares of $x$ and $z$ in total consumption are given by

$$
s_{x}=\frac{x}{\Phi} \frac{\partial \Phi}{\partial x} ; \quad s_{z}=\frac{z}{\Phi} \frac{\partial \Phi}{\partial z} .
$$




\subsection{Properties of optimal allocations: Step 1}

We now proceed to determine the properties of optimal allocations revealed by the $\psi$ function. Totally differentiating equation (2), we find that

$$
\frac{d x}{x}=-\left[\frac{1}{s_{z} \mu+\sigma s_{x}}\right] \frac{d \lambda}{\lambda}+\left[\frac{(\mu-\sigma) s_{z}}{s_{z} \mu+\sigma s_{x}}\right] \frac{d z}{z} .
$$

where we do not include country subscripts since we are describing general properties of the $\psi$ function. Note that (6) determines the elasticities of the $\psi$ function(s), which we denote by

$$
\begin{aligned}
\eta^{\lambda} & \equiv-\left[\frac{1}{s_{z} \mu+\sigma s_{x}}\right] \\
\eta^{z} & \equiv\left[\frac{(\mu-\sigma) s_{z}}{s_{z} \mu+\sigma s_{x}}\right] .
\end{aligned}
$$

Equation (6) tells us whether an increase in $z$ raises or lowers the optimal level of $x$, holding fixed the shadow price $\lambda$. If the substitution of $x$ for $z$ within the consumption aggregator is small (i.e., if $\mu$ is large relative to $\sigma$ ), then marginal utility of $x$ increases with $z$, and it is optimal to allocate larger quantities of the traded good to countries with higher endowments of the nontraded good. Conversely, if $\mu$ is small relative to $\sigma$ so that the marginal utility of $x$ decreases with $z$, then the optimal allocation involves lower provision of the traded good to countries experiencing relatively high endowments of the nontraded good. If the function $\psi$ is interpreted as a Frisch [19xx] demand curve for $x$, then an increase in $z$ is a positive demand shifter for the traded good if $\mu-\sigma>0$, and a negative demand shifter if $\mu-\sigma<0 .{ }^{2}$

In our analysis below, we will allow the elasticities $\eta^{\lambda}$ and $\eta^{z}$ to differ by country, where countries are distinguished by the subscript $j=1,2, \ldots, J$. These elasticities may differ across countries because the ratio $\pi / \omega$ differs across countries or because the benchmark level of $z$ at which the elasticities are evaluated differs across countries. We will interpret the response described in (6) as describing the effect of small stochastic displacements in the exogenous variables of the model economy.

\subsection{Properties of optimal allocations: Step 2}

An additional requirement is that the Pareto optimal allocations are resource-feasible. Totally differentiating the resource constraint (1) we obtain the following, which determines the effect on $\lambda$ of changes in the endowments of the traded and nontraded goods:

$$
\frac{d X}{X}=\sum_{j=1}^{J} \theta_{j} \eta_{j}^{\lambda} \frac{d \lambda}{\lambda}+\sum_{j=1}^{J} \theta_{j} \eta_{j}^{2} \frac{d z_{j}}{z_{j}}=\sum_{j=1}^{J} \theta_{j} \eta_{j}^{\lambda} \frac{d \lambda}{\lambda}+\eta^{Z} \frac{d Z}{Z}
$$

\footnotetext{
${ }^{2} \mathrm{~A}$ similar line of reasoning concerning the relative importance of $\mu$ versus $\sigma$ can be found in Tesar $(1993,1994)$ and Pesenti and van Wincoop (1994).
} 
where $\theta_{j}=\pi_{j} x_{j} / X$ and the latter equality follows from the definitions $\eta^{Z} \equiv \sum_{j=1}^{J} \theta_{j} \eta_{j}^{z}$ and $d Z=\left[\sum_{j=1}^{J} \theta_{j} \eta_{j}^{z} \frac{d z_{j}}{z_{j}}\right] / \eta^{Z}$. Using this result together with equation (6), we find that, for country $i$,

$$
\frac{d x_{i}}{x_{i}}=\frac{\eta_{j}^{\lambda}}{\sum_{j=1}^{J} \theta_{j} \eta_{j}^{\lambda}} \frac{d X}{X}-\frac{\eta_{i}^{\lambda}}{\sum_{j=1}^{J} \theta_{j} \eta_{j}^{\lambda}} \eta^{Z} \frac{d Z}{Z}+\eta_{i}^{z} \frac{d z_{i}}{z_{i}}
$$

where the first two terms are the effects of aggregate displacements operating through $\lambda$.

This pair of expressions reveals the core economics of our multi-country model. From equation (7) we have the intuitive result that the world marginal utility of $X$ falls with increases in $X$ since $\sum_{j=1}^{J} \theta_{j} \eta_{j}^{\lambda}<0$. Further, the effect on $\lambda$ of an increase in $z_{j}$ depends on the sign of $\eta_{j}^{z}$ and on the importance of country $j$ in the world economy, as reflected in $\theta_{j}$. Further, we can view $\lambda$ as influenced by a world supply shock to the traded good, $d X / X$, and a world demand shock $d Z / Z$. From equation (8), we see that there is a positive effect of the world traded good supply shock $d X / X$ on the allocation of country $i$ and that there are also effects of the country's nontraded goods outcome $\left(d z_{i} / z_{i}\right)$ and those in the rest of the world $(d Z / Z)$.

If the various countries have equal elasticities $\eta_{i}^{z}=\eta^{z}=\eta^{Z}$, and $\eta_{i}^{\lambda}=\eta^{\lambda}$, then we have the following version of $(8)$ :

$$
\frac{d x_{i}}{x_{i}}=\frac{d X}{X}+\eta^{Z}\left(\frac{d z_{i}}{z_{i}}-\frac{d Z}{Z}\right) .
$$

where $d Z / Z \equiv \sum_{j=1}^{J} \theta_{j}\left(d z_{j} / z_{j}\right)$.

In (9), changes in world supplies of $X$ are shared equally if $\eta^{Z}=0$. If $\eta^{Z} \neq 0$, then an additional reallocation of the traded good is undertaken based on an individual country's endowment of the nontraded good relative to the world average. Thinking about the nontraded good as producing shifts in the demand for the traded good, equation (9) is very intuitive: changes in world demand for $x$ must be frustrated by adjustments in its shadow price $(\lambda)$ since there is an exogenously given stock to be allocated. It is only if there is a relative demand shock that a country's allocation is affected.

\section{Analysis of supporting portfolios}

In the preceding section, we provided a characterization of ex-post Pareto optimal allocations in a multi-country model with random endowments of traded and nontraded goods. We found that each country should consume its endowment of the traded good and that the allocation of the non-traded good would take the general form $x_{i}=\Psi_{i}\left(X,\left\{z_{j}\right\}_{j=1}^{J},\left\{\pi_{j}\right\}_{j=1}^{J},\left\{\omega_{j}\right\}_{j=1}^{J}\right)$. As in the traditional general equilibrium theory of Arrow (1964) and Debreu (1959), the optimal allocations corresponding to 
a specific choice of welfare weights $\left(\left\{\omega_{j}\right\}_{j=1}^{J}\right)$ and population weights $\left(\left\{\pi_{j}\right\}_{j=1}^{J}\right)$ can be realized as an outcomes to an ex-ante market equilibrium with complete contingent claims, i.e., claims that payoff a unit of the traded good conditional if the state of nature is a specific realization of the vector $\left(X,\left\{z_{j}\right\}_{j=1}^{J}\right)$ and zero otherwise. ${ }^{3}$ In this paper, however, we are interested in describing a market equilibrium in terms of securities that are claims to the endowments in all states of nature rather than a single one. We accordingly restrict attention to a world of "small shocks," where we will show that it is generally possible to support optimal allocations for each country $j$ by holding a portfolio that is a claim to the world's traded goods endowments, a claim to the world's nontraded good endowment (suitably defined) and a claim to country j's nontraded good.

To this end, recall that the optimal allocation of the traded good for an individual country depended on world endowments of the traded and nontraded good, and on the country's endowment of the nontraded good. That is: equation (8) was of the form

$$
d x_{j}=\alpha_{j}^{X} d X+\alpha_{j}^{Z} d Z+\alpha_{j}^{z} d z_{j} .
$$

Viewing $d X, d Z$, and $d z_{j}$ as three sources of uncertainty in country $j$, equation (10) shows how optimal allocations - and optimal portfolio returns - must respond to the various sources of uncertainty.

\subsection{Asset payoffs}

We let the traded good function as numeraire in this economy. We define an "equity claim" on a in this atemporal world to be a claim to a stream of "dividends" (i.e., the stream of endowments of a particular good) denominated in units of the traded good. For example, an equity claim on country $i$ 's nontraded good will pay out $d \mathbf{n}_{j} \equiv d\left(p_{j} z_{j}\right)$. That is: the equity claim on the nontraded good will vary with changes in $z_{j}$, but will also vary with changes in $p_{j}$, the relative price of $z$. Solving out for $d p_{j}$ using equation (5) we have:

$$
d \mathbf{n}_{j} \equiv d\left(p_{j} z_{j}\right)=\left(\frac{p_{j} z_{j}}{x_{j}} \mu_{j}\right) d x_{j}+\left(p_{j}\left(1-\mu_{j}\right)\right) d z_{j}
$$

Substituting for the optimal allocation $d x_{i}$ from equation (10) we have ${ }^{4}$

$$
d \mathbf{n}_{j}=\left(\frac{p_{j} z_{j}}{x_{j}} \mu_{j} \alpha_{j}\right) d X+\left(\frac{p_{j} z_{j}}{x_{j}} \mu_{j} \alpha_{j}^{z}\right) d Z+\left(\frac{p_{j} z_{j}}{x_{j}} \mu_{j} \alpha_{i}^{z}+p_{j}\left(1-\mu_{j}\right)\right) d z_{j}
$$

\footnotetext{
${ }^{3}$ The specific allocation corresponding to $\left(\left\{\pi_{j}\right\}_{j=1}^{J},\left\{\omega_{j}\right\}_{j=1}^{J}\right)$ also typically requires a transfer of wealth across countries unless there is a particular value of the welfare weights $\left(\left\{\omega_{j}\right\}_{j=1}^{J}\right)$.

${ }^{4}$ Note that, when $\mu_{j}=1, d z_{j}$ continues to affect $d \mathbf{n}_{j}$, but it does so through $d x_{j}$. Further, in this case, $d \mathbf{n}_{j}$ is perfectly collinear with $d x_{j}$.
} 
The domestic nontraded good equity pays off $d\left(p_{j} z_{j}\right)$, given by equation (11) above. That is, it has a payoff structure of the form:

$$
d \mathbf{n}_{j}=\Lambda_{j}^{X} d X+\Lambda_{j}^{Z} d Z+\Lambda_{j}^{z} d z_{j}
$$

with "payoff loadings" given by the coefficients in (11).

A world portfolio of nontraded good equities, where $w_{j}$ denotes the portfolio share of country $j$, is denoted by $\mathbf{N}$ and has payoff equal to:

$$
d \mathbf{N}=\sum_{j=1}^{J} w_{j} d \mathbf{n}_{j}
$$

Using the payoff structure in equation (12), we have

$$
d \mathbf{N}=\sum_{j=1}^{J}\left(w_{j} \Lambda_{i}^{X}\right) d X+\sum_{j=1}^{J}\left(w_{j} \Lambda_{j}^{Z}\right) d Z+\sum_{j=1}^{J}\left(w_{j} \Lambda_{j}^{z}\right) d z_{j} .
$$

Equation (13) shows that the return on the world portfolio of nontraded goods will generally depend on the distribution of the nontraded goods across countries, as seen by the last term of this equation. Ideally, we would like the return to the world portfolio of nontraded goods to depend only on the world endowments of traded and nontraded goods, i.e., we would like $d \mathbf{N}$ to depend only on $d X$ and $d Z$. This can be accomplished by choosing the portfolio weights $w_{j}$ to satisfy

$$
w_{j} \Lambda_{j}^{z}=W \frac{\theta_{j} \eta_{j}^{z}}{z_{j} \eta^{Z}}
$$

so that $\sum_{j=1}^{J}\left(w_{j} \Lambda_{j}^{z}\right) d z_{j}=W(d Z)$. Further, requiring that $\sum_{j=1}^{J} w_{j}=1$ determines the constant $W=\left[\sum_{j=1}^{J}\left(\theta_{j} \eta_{j}^{z} /\left(z_{j} \eta_{z} \Lambda_{j}^{z}\right)\right)\right]^{-1}$. With the portfolio weights determined in this way, we may write

$$
d \mathbf{N}=\sum_{j=1}^{J}\left(w_{j} \Lambda_{j}^{X}\right) d X+\sum_{j=1}^{J}\left(w_{j} \Lambda_{j}^{Z}+W\right) d Z .
$$

which is a payoff structure of the form:

$$
d \mathbf{N}=\Lambda_{N}^{X} d X+\Lambda_{N}^{Z} d Z
$$

i.e., one that depends only on the aggregate factors $d X$ and $d Z$, as desired.

Consider finally a portfolio representing a claim to the world endowment of the traded good, which we denote by $\mathbf{T}$. Recalling that $\xi_{j}$ denotes country $j$ 's endowment of the traded good, we have $\mathbf{T}=\sum_{j=1}^{J} \pi_{j} \xi_{j}=X$, so that

$$
d \mathbf{T}=d X .
$$

which is a payoff structure with a single factor and a unit factor loading. 


\subsection{Individual expenditure}

In order to purchase his optimal allocation, an individual living in country $i$ must have purchasing power or expenditure (in units of the traded good) equal to

$$
e_{j} \equiv x_{j}+p_{j} z_{j}
$$

The displacement in expenditure arising from displacements in world and national endowments is given by (using equation (13) above)

$$
d e_{j}=\left(\alpha_{j}^{X}+\Lambda_{j}^{X}\right) d X+\left(\alpha_{j}^{Z}+\Lambda_{j}^{Z}\right) d Z+\left(\alpha_{j}^{z}+\Lambda_{j}^{z}\right) d z_{j} .
$$

where the form of this expression reflects the fact that the sensitivity of $e_{j}$ to $X, Z$, and $z_{j}$ is just a result of the sum of the sensitivities of $x_{j}$ and $p_{j} z_{j}$ to these factors. For convenience in some of the derivations below, we define

$$
d e_{j}=\varepsilon_{j}^{X} d X+\varepsilon_{j}^{Z} d Z+\varepsilon_{j}^{z} d z_{j} .
$$

Further, this expression suggests that one way to generate the income necessary to buy the optimal allocation is to hold appropriate quantities of three assets: the asset representing a claim on the world endowment of the traded good; the asset representing a claim on the world endowment of the nontraded good; and the asset representing a claim on the individual's home country endowment of the nontraded good. However, the appropriate shares in each of these portfolios are not given by the coefficients on $d X, d Z$, and $d z_{j}$ in equation (17), since the returns on the nontraded assets in general depend on all three of these 'factors.'

\subsection{Basic securities}

In the preceding sub-sections, we determined the returns to various "equities" as functions of movements in the three basic assets: the world endowment of the traded good, the world endowment of the nontraded good, and the individual country endowment of the traded good. Collecting up these three expressions (equations (16), (13), and (11)) and, as before, using the notation $\Lambda_{A}^{B}$ to denote the coefficient (or "loading") on $B$ in the expression for the return on $A$, we note that we have a recursive system of equations for the complex securities:

$$
\begin{gathered}
d \mathbf{T}=d X \\
d \mathbf{N}=\Lambda_{N}^{X} d X+\Lambda_{N}^{Z} d Z \\
d \mathbf{n}_{j}=\Lambda_{j}^{X} d X+\Lambda_{j}^{Z} d Z+\Lambda_{j}^{z} d z_{j} .
\end{gathered}
$$

It is thus straightforward to create the basic securities as:

$$
d X=d \mathbf{T}
$$




$$
\begin{gathered}
d Z=\left(\frac{1}{\Lambda_{N}^{Z}}\right) d \mathbf{N}+\left(-\frac{\Lambda_{N}^{X}}{\Lambda_{N}^{Z}}\right) d \mathbf{T} \\
d z_{j}=\left(\frac{\Lambda_{j}^{Z}}{\Lambda_{j}^{z}} \frac{\Lambda_{N}^{X}}{\Lambda_{N}^{Z}}-\frac{\Lambda_{j}^{X}}{\Lambda_{j}^{z}}\right) d \mathbf{T}+\left(-\frac{1}{\Lambda_{N}^{Z}} \frac{\Lambda_{j}^{Z}}{\Lambda_{j}^{z}}\right) d \mathbf{N}+\left(\frac{1}{\Lambda_{j}^{z}}\right) d \mathbf{n}_{j}
\end{gathered}
$$

\subsection{Supporting optimal consumption}

Having determined how to construct the basic securities as linear combinations of the real securities, it is straightforward to characterize the quantities of each of these real securities that an individual must hold in order to be able to purchase his optimal consumption basket. Recall that the expenditure required to purchase the optimal consumption bundle was given by $d e_{j}=\varepsilon_{j}^{X} d X+\varepsilon_{j}^{Z} d Z+\varepsilon_{j}^{z} d z_{j}$. Substituting for $d X$, $d Z$, and $d z_{j}$ from (18)-(20), we have:

$$
d e_{j}=\vartheta_{j}^{T} d \mathbf{T}+\vartheta_{j}^{N} d \mathbf{N}+\vartheta_{j}^{n} d \mathbf{n}_{j}
$$

where the coefficients on each of the complex securities are:

$$
\begin{gathered}
\vartheta_{j}^{T}=\varepsilon_{j}^{X}-\left(\frac{\Lambda_{N}^{X}}{\Lambda_{N}^{Z}}\right) \varepsilon_{j}^{Z}+\left(\frac{-\Lambda_{j}^{X}}{\Lambda_{j}^{z}}+\frac{\Lambda_{j}^{Z}}{\Lambda_{j}^{z}} \frac{\Lambda_{N}^{X}}{\Lambda_{N}^{Z}}\right) \varepsilon_{j}^{z} \\
\vartheta_{j}^{N}=\left(\frac{1}{\Lambda_{N}^{Z}}\right) \varepsilon_{j}^{Z}-\left(\frac{1}{\Lambda_{N}^{Z}} \frac{\Lambda_{j}^{Z}}{\Lambda_{j}^{z}}\right) \varepsilon_{j}^{z} \\
\vartheta_{j}^{n}=\left(\frac{1}{\Lambda_{j}^{z}}\right) \varepsilon_{j}^{z} .
\end{gathered}
$$

\subsection{Interpreting the portfolio allocations}

It is easiest to begin by considering portfolio allocations for the basic securities. These holdings produce the payoffs necessary to support the optimal consumption bundle when there are changes in $X, Z$, or $z_{j}$. From above, we know that holdings of the domestic nontraded good portfolio are given by:

$$
\varepsilon_{j}^{z}=\alpha_{j}^{z}+\Lambda_{j}^{z}
$$

Thus when $d z_{j}>0$, expenditure may be high (i) due to increases in the optimal allocation of $x$ to country $j$ (if $\alpha_{j}^{z}=\partial x_{j} / \partial z_{j}>0$ ); or (ii) due to increases in world cost of purchasing nontraded goods (if $\Lambda_{j}^{z}=\partial\left(p_{j} z_{j}\right) / \partial z_{j}>0$ ). Similar considerations govern the portfolio shares devoted to the other basic securities, i.e., $\varepsilon_{j}^{X}=\alpha_{j}^{X}+\Lambda_{j}^{X}$ and $\varepsilon_{j}^{Z}=\alpha_{i j}^{Z}+\Lambda_{j}^{Z}$.

Portfolio allocations in terms of real securities generally involve two sets of considerations. First, how much sensitivity should there be to the two underlying economic 
factors described above? In this regard, they are governed by the same considerations as for basic security allocations, namely the $\varepsilon$ coefficients. Second, what portfolio manipulations must be undertaken to effectively produce basic securities from market securities?

Let's look first at the demand for $\mathbf{n}_{j}$ as determined above. Using the definition of $\varepsilon_{j}^{z}$, we have:

$$
\vartheta_{j}^{n}=\frac{\varepsilon_{j}^{z}}{\Lambda_{j}^{z}}=1+\frac{\alpha_{j}^{z}}{\Lambda_{j}^{z}}
$$

If utility is additively separable in traded and nontraded goods $\left(\alpha_{j}^{z}=\partial x_{j} / \partial z_{j}=0\right)$, $\vartheta_{j}^{n}=1$. In this case, each country holds all of the claims to its own nontraded goods equity because it is a perfect hedge for nontraded goods consumption. ${ }^{5}$ Departures from this case occur when it is desirable to alter traded goods consumption with $d z_{j}$. The magnitude of the adjustment is governed by two factors. The first factor is the sensitivity of $x_{j}$ to $z_{j}$, i.e., the value of $\alpha_{j}^{z}=\partial x_{j} / \partial z_{j}$. The second factor is the sensitivity of $\mathbf{n}_{j}$ payoffs to $z_{j}$, i.e., the value of $\Lambda_{j}^{Z}$. The next section takes a closer look at these two forces in the context of a particular example in which all countries are parameterized symmetrically.

\section{The symmetric case}

This section presents results for a world economy in which all countries are identical in terms of initial conditions, although they are subject to different shocks to their endowments of traded and nontraded goods. That is: we assume the following initial conditions: $x_{j}=x=X, z_{j}=z, p_{j}=p$, and $\pi_{j}=1 / J$ for each country $j$. With identical preferences across countries, the central elasticities are the same across countries: $\eta_{j}^{\lambda}=\eta^{\lambda}, \eta_{j}^{z}=\eta^{z}=\eta^{Z}, \mu_{j}=\mu$ for each country $j$.

\subsection{Equilibrium portfolio weights}

To solve for the optimal portfolio allocation we can now simply follow the steps outlined for the general case, and after some algebra--whose details are in the appendixportfolio weights simplify significantly to:

$$
\begin{gathered}
\vartheta^{T}=1 \\
\vartheta^{n}=1+\left(\frac{x}{p z}\right) \frac{\eta^{Z}}{\mu \eta^{Z}+(1-\mu)} \\
\vartheta^{N}=-\left(\vartheta^{n}-1\right)
\end{gathered}
$$

\footnotetext{
${ }^{5}$ This is the case studied by Stockman and Dellas (1989).
} 
where holding a portfolio share of 1 corresponds to a country's share in the world portfolio.

As shown by $\vartheta^{T}=1$, it is never optimal to exhibit home bias in a portfolio of traded-good equity. We obtain this result despite nonseparable utility in the consumption of the traded and nontraded good. This conflicts with recent studies by Pesenti and vanWincoop (1994) and Tesar (1994) that made the auxiliary assumption that claims to nontraded goods could not be traded internationally. In their setups, home bias in the traded-good portfolio was possible, depending on preference parameters and covariance properties. Allowing for all claims to be traded, as seems more realistic, therefore overturns their findings.

With respect to claims in nontraded-good equity, we find that investors may hold more or less than $100 \%$ of domestic endowment, and that there is an important role for holding other countries'nontraded-good equity. Equation (22) indicates the extent to which an individual wishes to hold more or less than $100 \%$ of the claim on own nontraded goods. Equation (23) makes clear that the optimal share in the world portfolio of nontraded-good equity is closely related to the deviation from the $100 \%$ holding of domestic nontraded-good equity. In terms of our general model, Stockman and Dellas (1989) studied the parametric special case in which $\mu=\sigma$, so that $\eta^{Z}=0$. In this case, the coefficients above simplify to the following:

$$
\vartheta^{T}=1 ; \quad \vartheta^{n}=1 ; \quad \vartheta^{N}=0
$$

Thus, each individual receives his country's share of the world supply of the traded good, regardless of the realization of the nontraded good endowment in his country. And thus, the supporting portfolio consists of the individual's domestic share of the world traded goods portfolio, so that $\vartheta^{T}=1$, together with a claim on the entire nontraded good endowment of his country, $\vartheta^{n}=1$. In this economy there is no benefit to holding claims to the world nontraded good portfolio since the prior two components support the optimum, so that $\vartheta^{N}=0$.

\subsection{An interview with the representative agent}

We have found that, in the symmetric case, the portfolio weights on the real securities have a fairly intuitive form. Nevertheless, the ratio of algebra to economic intuition is higher than the authors would like. For this reason, we decided to interview the representative agent and let him give you some of the intuition behind his portfolio strategy.

Baxter, Jermann, and King (BJK): Could you tell us a little about your preferences?

Representative Agent (RA): I'm relatively risk averse: with $\sigma=2$. I have a fairly high elasticity of substitution between traded and nontraded goods, so for me, 
$\mu=0.4$.

BJK: You seem to be very confident about these numbers. Are you aware that some economists have argued that risk aversion may be as high as 30 and for $\mu$ some researchers have advanced a number of 3 , implying much less substitutability?

RA: That's the trouble with being the representative agent. Everyone has an opinion about whether your preferences make sense. But let's look at your Figure 1, at the end of the paper. This figure plots the optimal portfolio share in domestic nontraded good equities as a function of the parameter $\mu$. There are three regions in the graph, corresponding to different configurations of the coefficients $\alpha^{z}$ and $\Lambda^{z}$. In region I, we have $a^{z}<0$ so that optimal allocations of $x$ fall with endowments of $z$ (you remember that $\alpha^{z}$ has the same sign as $\mu-\sigma$ ). In region I we also have $\Lambda^{z}>0$, so that the return to the market claim to the nontraded good rises with the endowment of the nontraded good. In order to obtain a lower overall payout on my portfolio when the endowment of my own nontraded good is high, I must establish a short position in my own nontraded good equities.

BJK: But ....

RA: Just a minute-there's more. Look at what happens if the elasticity of substitution between traded and nontraded goods is rather low-that is: $\mu$ is high. In regions II and III, with higher values of $\mu$, we have $\Lambda^{z}<0$. This means that the return to the market claim to the nontraded good actually falls with the endowment of the nontraded good! The reason is that the relative price of the nontraded good falls so much when the endowment of the nontraded good is high, that the value of the nontraded good equity falls when the endowment is high. Now, did you ever read the following headline?

\section{MATTEL HAS BEST CHRISTMAS EVER-STOCK DROPS 20\%}

BJK: Um, no, not even in the National Enquirer. So your argument is that we should use the information that stock returns rise when output is high to restrict $\mu$ to a range that implies fairly high substitutability. Seems sensible.

$\mathrm{Ok}$-we understand your holdings of claims on your own nontraded good, but why do you hold any claims on the world portfolio of nontraded goods? If you're short your own nontraded good equities, you must be holding a lot of the nontraded good equities issued by other countries. Since you can't consume nontraded goods that arrive in other countries, so what good are these claims to you? 
RA: Think about this: when the RA's in other countries want to consume a lot $(d Z<0)$, it becomes costly for me to consume. So, I decide to reduce my consumption and therefore am well served with a world fund of nontraded industries that gives me a relatively low return in that state.

BJK: Okay, you've convinced us that your holdings of nontraded good equities make sense. But did you even consider holding more (or maybe less) of a claim on your own country's endowment of the traded good?

RA: No-absolutely not. Lesson \#1 in finance is: diversify. Lessons \#2-\#10 are also: diversify. We've been talking about alterations in holdings of various claims to nontraded goods because these act as effective hedges. That is: they hedge against variations in the marginal utility of consumption of the traded good caused by variations in the domestic and world endowments of the nontraded good. But why would I want to lose the benefits of diversification in holdings of the traded good? Doesn't make any sense at all.

BJK: A final question: can you explain the asymptote in Figure 1? How would an investor with this particular value of $\mu$ structure his portfolio?

RA The asymptote that divides region I from region II is the point at which $\Lambda^{z}$ changes sign. At this particular point, the price and the quantity effect from an endowment shock in the nontraded good's industry exactly offset each other: that is: the return to the domestic nontraded good portfolio does not depend on the endowment of the domestic nontraded good! In this case, the domestic nontraded good equity cannot be used to provide the required sensitivity of $x$ to variations in the endowment of the $z$ good. For this particular value of $\mu$, the decentralized economy cannot support the optimal allocations. In particular, we would have needed derivative securities to achieve complete markets.

BJK Well, that takes care of all of our questions. Thank you for your time.

RA: You're most welcome.

\section{Nontraded human capital}

This section considers the role of risk associated with returns to nontraded human capital in the presence of nontraded goods. The analysis is closely related to prior work by Baxter and Jermann (1993), which studied the role of nontraded human capital risk in a two-country world with a single tradable consumption good. Instead 
of assuming that goods arrive as non-produced endowments, suppose instead that they are produced by combining labor and capital according to a Cobb-Douglas, constantreturns-to-scale production technology in which capital and labor are exogenously supplied. ${ }^{6}$ As shown by Baxter and Jermann (1993), the payouts to capital and the returns to labor in each sector will be perfectly correlated, since each receives a fixed share of sectoral output.

Now, consider the fact that there is no traded asset whose payoff is explicitly contingent on the return to human capital (labor) in either sector. Since the payoff to physical capital is perfectly correlated with the payoff to nontraded human capital, a claim to physical capital can be used to hedge the risk associated with nontraded human capital. We follow Black (1987) in identifying the traded claims on firms as the appropriate measure of claims to the payouts of physical capital. For concreteness, we call these traded claims the national "equity market' which is somewhat misleading since it would also include corporate debt.

In the single traded good model of Baxter and Jermann, the hedge is constructed as follows. Let $s_{K}$ denote the share of capital in aggregate output, and let $s_{L}=1-s_{K}$ denote labor's share (i.e., the share of human capital) in aggregate output. Since, in the United States, labor's share is approximately two-thirds, the national equity market represents about $s_{K}=1 / 3$ of aggregate wealth, with nontraded human capital representing the remaining $s_{L}=2 / 3$. Thus the hedge is establishing by selling short the domestic equity market in an amount equal to $s_{L}$ of investor wealth, or $s_{L} / s_{K}=2$ times the value of the national equity market. Having hedged the risk associated with nontraded human capital, the investor then constructs his optimal portfolio. A simple portfolio strategy is simply to hold the world portfolio of traded equities, where each country's weight in the world portfolio is given by $\Gamma_{j}=1,2, \ldots, J$, with $\sum_{j=1}^{J} \Gamma_{j}=1$. In this case, the net position held by the domestic investor in country $j$ (as a fraction of investor wealth) is given by $\Gamma_{j}-s_{L}$; as a fraction of the national equity market the net position is $\left(\Gamma_{j}-s_{L}\right) / s_{K}$. For the United States, which represented about of $1 / 2$ of world equity markets in 1991, the net position would be a short position equal to $(0.67-0.50) / 0.33=0.51(51 \%)$ of the national stock market. For countries representing smaller fractions of the world equity market (smaller $\Gamma_{j}$ ), the short position in national equities would be even larger (in absolute value). The U.K., for example, represented $15 \%$ of the world equity market in 1991, which would imply a short position in national equities of $158 \%$ of the equity market (assuming that labor's share is $2 / 3$ ). Intuitively, these results reflect the fact that nontraded human capital represents a very large fraction of aggregate wealth, so that large negative positions in national equities are needed to hedge the associated risk. So long as labor's share in a particular country exceeds the country's share in the world portfolio, the net position in national equities will be negative. Further, as the results above indicate, the short position will be larger (in absolute value) the smaller the country's share in

\footnotetext{
${ }^{6}$ The Cobb-Douglas technology delivers the constancy of factor shares that appears to be a good approximation to the experiences of developed economies.
} 
the world portfolio.

Having reviewed the results for an economy with a single traded good, we now consider how these results are modified when there are both traded and nontraded goods. For the traded good, the Baxter-Jermann results go through directly. Recall that the optimal portfolio involved holding exactly your country's share of the traded good; in our earlier analysis, the investor simply held his country's share of the claims to the world endowment of the traded good. In the present setup, the investor receives $s_{L X} \xi_{j}$ of the payoff from the domestic traded good as a nontraded return to human capital (where $s_{L X}$ denotes the share of labor income in the traded goods industry, assumed for simplicity to be identical across countries). The remainder of the payoff from the domestic traded good, $s_{K X} \xi_{j}=\left(1-s_{L X}\right) \xi_{j}$ is the payoff to the traded claim ("equity") on the domestic traded good. Since the investor wants to hold simply a claim to the world endowment of the traded good, he follows exactly the procedure described above. First, he hedges the nontraded labor income by establishing a short position in the domestic traded-good equity equal to $s_{L X} \xi_{j} / s_{K X} \xi_{j}=s_{L X} / s_{K X}$ (as a fraction of the market in domestic traded good equity). He then would use the proceeds to purchase the world traded good portfolio, of which his country's share is $\pi_{j}$ (or $1 / J$ in the symmetric case). Thus, as before, his net position in the domestic traded-good equity, as a fraction of that market, is given by $\left(-s_{L X}+\right.$ $\left.\pi_{j}\right) / s_{K X}$. Assuming the labor's share in traded goods is approximately the same as it is in aggregate output, the analysis above suggests a short position in national traded-goods equities of about $51 \%$ for the United States, and about $158 \%$ for the U.K.

Now, consider how the presence of nontraded human capital alters the optimal holdings of the equity claim on domestic nontraded goods. In section 4 we showed that the optimal portfolio contained a fraction $\vartheta_{j}^{n}=1+\kappa_{j}$ of the domestic nontraded good which, in the symmetric case studied in section 5 , is equal to

$$
\vartheta_{j}^{n}=1+\left(\frac{x}{p z}\right) \frac{\eta^{Z}}{\mu \eta^{Z}+(1-\mu)}
$$

In the nontraded goods sector, labor receives the share $s_{L Z} \zeta_{j}=s_{L Z} z_{j}$ of sectoral output, and capital receives $s_{K Z} \zeta_{j}=s_{K Z} z_{j}=\left(1-s_{L Z} z_{j}\right)$. If the individual holds $100 \%$ of the equity claim on the nontraded goods sector together with the nontraded labor income from this sector, his holdings of the nontraded good are $\vartheta_{j}^{n}=1$. To achieve the optimal holdings $\vartheta_{j}^{n}=1+\kappa_{j}$ (as a fraction of investor wealth), the investor must purchase additional units of the domestic nontraded good equity in the amount $\kappa_{j} / s_{K Z}$.

Consider the case in which $\mu<\sigma$ so that $\eta^{Z}<0$, and $\vartheta_{i}^{n}<1$, or $\kappa_{i}<0$. Suppose that, absent human capital considerations, $\kappa_{j}=-0.20$, so that the optimal holdings of the domestic nontraded good equity represented $80 \%$ of the market in that equity. When we introduce nontraded human capital, the optimal portfolio share in the domestic nontraded good equity drops to $\vartheta_{j}^{n}=1+\kappa_{j} / s_{K Z}=1+(-0.20 / 0.33)=0.40$. 
In the opposite case, in which $\mu>0$ and $\eta^{Z}>0$, optimal holdings of the domestic nontraded good equity exceed one. If, for example, $\vartheta_{j}^{n}=1.15$ absent human capital considerations (implying $\kappa_{j}=0.15$ ), then incorporating human capital increases the optimal share in the domestic nontraded good equity to $\vartheta_{j}^{n}=1+\kappa_{j} / s_{K Z}=1.45$.

To summarize, there are two important effects of incorporating nontraded human capital. First, for holdings of the equity associated with the traded good, the BaxterJermann analysis goes through unchanged. So long as labor's share exceeds the nation's share in the world equity market, as seems plausible for every country in the world, the net position in the country's traded good equity will be negative. Further, this short position will be larger (in absolute value) the smaller the country's share in the world equity market. Second, the presence of nontraded human capital amplifies the deviation of the optimal portfolio holdings of the nontraded good equity from the Stockman-Dellas benchmark in which the investor holds $100 \%$ of equities on the nontraded good. That is: if the investor holds less than $100 \%$ of domestic nontraded good equity absent human capital considerations, say $100(1-\kappa) \%$, he will hold approximately $100(1-3 \kappa) \%$ once nontraded human capital is incorporated into the analysis.

\section{Conclusion}

This paper has studied the role of nontraded goods in generating "home bias" in investor portfolios. Specifically, we studied the problem of optimal portfolio choice in a world economy in which each country has a traded and a nontraded good. Like earlier studies, we restrict attention to the case in which the quantities of these goods arrive as endowments. In contrast to earlier studies, however, we adopt the strategy of explicitly characterizing Pareto optimal allocations of the traded good across countries as in standard general equilibrium theory. When we do this in an endowment setting, we find that time per se is unimportant: what matters for the allocation of the traded good across economies are (i) the realizations of endowments of traded and nontraded goods; and (ii) welfare and resource weights. We thus focus our attention on an atemporal resource allocation problem. We choose to study attributes of this resource allocation problem using linear approximation methods as is conventional in static international trade analyses following Jones (1965). One benefit of this approach is thus that our results depend on aspects of the economy familiar from many studies in international economics: the response of allocations to endowment perturbations depends on elasticities, shares, etc. in conventional ways.

Our main finding is that nontraded goods are unlikely to rationalize home bias. First, leaving aside for the moment the issue of nontraded human capital, the portfolio composition predictions of the nontraded good model are at odds with the empirical facts. That is: our model predicts that investors should hold a diversified world portfolio of traded-good equities, so that their holdings of their own country's traded-good equities will typically be very small. For nontraded good equities, there 
may be substantial home bias, depending on the extent of substitutability in consumption between the nontraded and traded goods. However, this result requires a very low degree of substitutability between traded and nontraded goods in the utility function-sufficiently low that the payout to the nontraded good equity falls with increases in the endowment of the nontraded good. In terms of the empirical predictions regarding composition of portfolios, it does not appear that investors or mutual fund managers attempt to structure portfolios with very different shares in "traded good equities" and "nontraded good equities."

Second, when we consider the portfolio implications of incorporating nontraded human capital, the model fails to explain both the level and the composition of investor portfolios. Building on the work of Baxter and Jermann (1993), we show that hedging the risk associated with the nontraded human capital involves an overall short position in domestic traded-goods equities. For nontraded goods, the incorporation of human capital amplifies the deviation from the Stockman-Dellas (1989) benchmark holdings of $100 \%$ of domestic nontraded-good equities. Thus, with nontraded human capital, the level of domestic holdings becomes smaller, and the divergence between holdings of traded good equities and nontraded good equities widens.

Our results suggest that home bias is not a rational response by investors to an environment with both traded and nontraded goods. Rather, these results suggest that there should be important gains to international diversification, even in the presence of nontraded consumption goods. ${ }^{7}$ Although international diversification is increasing over time, the extent of home bias that remains suggests that there may still be important, although subtle, barriers to international diversification. Two examples of such barriers are (i) restrictions on the fraction of foreign assets that may be held by insurance companies and pension funds; and (ii) withholding taxes on foreign residents' returns on government securities, the rebating of which is cumbersome and time-consuming. Removal of such barriers could improve the risk-return tradeoff faced by investors, and could finally resolve the international diversification puzzle.

\footnotetext{
${ }^{7}$ Lewis (1994) provides an overview of the literature on the costs of non-diversification, and explores the reasons behind the divergent estimates of the costs obtained by a consumption-based approach versus a financial market-based approach.
} 


\section{A Appendix}

This appendix contains the mathematical details behind some of the results for the symmetric economy discussed in Section 4.

\section{A.1 Optimal allocations of the traded good}

We first work out the implications for the coefficients in the expression for the relationship between the optimal traded good allocation to the three basic securities (equation (10), reproduced below):

$$
d x_{i}=\alpha_{i}^{X} d X+\alpha_{i}^{Z} d Z+\alpha_{i}^{z} d z_{i}
$$

where

$$
\begin{gathered}
\alpha_{i}^{X}=\frac{\eta_{i}^{\lambda}}{\sum_{j=1}^{N} \theta_{j} \eta_{j}^{\lambda}} \frac{x_{i}}{X} \\
\alpha_{i}^{Z}=-\frac{\eta_{i}^{\lambda} \eta^{Z}}{\sum_{j=1}^{N} \theta_{j} \eta_{j}^{\lambda}} \frac{x_{i}}{Z} \\
\alpha_{i}^{z}=\eta_{i}^{z} \frac{x_{i}}{z_{i}}
\end{gathered}
$$

In the symmetric case under consideration here, these expressions become much simpler. Using the fact that elasticities are the same across countries, and that $\sum_{j=1}^{N} \theta_{j}=1$ and $Z=1$, we have

$$
\begin{gathered}
\alpha_{i}^{X}=1 \\
\alpha_{i}^{Z}=-\eta^{Z}\left(\frac{X}{Z}\right)=-\eta^{Z} X \\
\alpha_{i}^{z}=\eta^{z}\left(\frac{x}{z}\right)=\eta^{Z}\left(\frac{x}{z}\right) .
\end{gathered}
$$

Thus, when countries are identical ex ante, the sensitivity of optimal allocations to shocks is the same in every country.

\section{A.2 Value of the domestic nontraded good dividends}

We now work out the implications of symmetry for the coefficients in the expression

$$
d \mathbf{n}_{j} \equiv d\left(p_{j} z_{j}\right)=\Lambda_{j}^{X} d X+\Lambda_{j}^{Z} d Z+\Lambda_{j}^{z} d z_{j}
$$

We know that

$$
\frac{d\left(p_{j} z_{j}\right)}{p_{j} z_{j}}=\frac{d p_{j}}{p_{j}}+\frac{d z_{j}}{z_{j}}=\mu_{j}\left(\frac{d x_{j}}{x_{j}}-\frac{d z_{j}}{z_{j}}\right)+\frac{d z_{j}}{z_{j}}
$$


so, after a little algebra, we have

$$
d\left(p_{j} z_{j}\right)=\mu_{j}\left(\frac{p_{j} z_{j}}{x_{j}}\right) d x_{j}+p_{j}\left(1-\mu_{j}\right) d z_{j}
$$

Substituting from (24) we have

$$
d\left(p_{j} z_{j}\right)=\mu_{j}\left(\frac{p_{j} z_{j}}{x_{j}}\right) \alpha_{j}^{X} d X+\mu_{j}\left(\frac{p_{j} z_{j}}{x_{j}}\right) \alpha_{j}^{Z} d Z+\left[\mu_{j}\left(\frac{p_{j} z_{j}}{x_{j}}\right) \alpha_{j}^{z}+p_{j}\left(1-\mu_{j}\right)\right] d z_{j}
$$

Using the facts that $\mu_{j}=\mu, p_{j} z_{j}=p z, x_{j}=x$ and the results from above, we have

$$
\Lambda_{j}^{X}=\mu\left(\frac{p z}{x}\right) \alpha^{X}=\mu\left(\frac{p z}{x}\right)
$$

Thus the expression for $d \mathbf{n}_{j}$ in terms of the basic securities reduces to:

$$
d \mathbf{n}_{j}=\mu\left(\frac{p z}{x}\right) d X-\mu(p z) \eta^{Z} d Z+p\left(\mu \eta^{Z}+(1-\mu)\right) d z_{j}
$$

Note that, if $\eta^{Z}<0, \mu<1$ is a necessary but not a sufficient condition for $d \mathbf{n}_{j}$ to respond positively to $d z_{j}$. Further, from equation (27), we see that $d \mathbf{n}_{j}$ responds positively to $d X$ since increases in the world endowment of the traded good reduce the shadow price $\lambda$ and raise the allocation of $X$ to every country. In turn, $d \dot{X}>0$ raises the relative price of the nontraded good.

In section 4 above we showed that the dividend on country $j^{\prime} s$ nontraded good claim was given by $d \mathbf{n}_{j} \equiv d\left(p_{j} z_{j}\right)=\Lambda_{j}^{X} d X+\Lambda_{j}^{Z} d Z+\Lambda_{j}^{z} d z_{j}$, so that the dividend on the world nontraded good portfolio is given by

$$
d \mathbf{N}=\sum_{j=1}^{J} w_{j} \Lambda_{j}^{X} d X+\sum_{j=1}^{J} w_{j} \Lambda_{j}^{Z} d Z+\sum_{j=1}^{J} w_{j} \Lambda_{j}^{z} d z_{j}
$$

In the symmetric case, we can drop the $j$ subscripts on the $\Lambda$ coefficients, yielding

$$
d \mathbf{N}=\Lambda^{X} d X+\Lambda^{z} d Z+\Lambda^{z} \sum_{j=1}^{J} w_{j} d z_{j}
$$

with $w_{j}=1 / J$. Recall that our definition of $d Z$ was

$$
d Z=\sum_{j=1}^{J} \theta_{j}\left(\frac{\eta_{j}^{z}}{\eta^{Z}}\right) \frac{d z_{j}}{z_{j}}
$$

Thus, since in the symmetric case $\theta_{j}=\pi_{j}\left(x_{j} / X\right)=1 / J, \eta_{j}^{z}=\eta^{Z}$ and $z_{j}=z$, we can write

$$
d \mathbf{N}=\Lambda^{X} d X+\left(Z \Lambda^{Z}+z \Lambda^{z}\right) d Z=\Lambda^{X} d X+\left(\Lambda^{z}+z \Lambda^{z}\right) d Z
$$


making the coefficients

$$
\begin{gathered}
\Lambda_{N}^{X}=\Lambda^{X} \\
\Lambda_{N}^{Z}=\Lambda^{Z}+z \Lambda^{z} .
\end{gathered}
$$

After substituting for $\Lambda^{z}$ and $z \Lambda^{z}$ from equations (26)-(??), equation (28) becomes

$$
\Lambda_{N}^{Z}=-\mu(p z) \eta^{Z}+(p z)\left(\mu \eta^{Z}+(1-\mu)\right)=(p z)(1-\mu) .
$$

Thus the expression for $d \mathbf{N}$ in terms of basic securities simplifies to

$$
d \mathbf{N}=\mu\left(\frac{p z}{x}\right) d X+(p z)(1-\mu) d Z=\mu(p z) \frac{d X}{X}+(1-\mu)(p z) \frac{d Z}{Z} .
$$

Thus the world nontraded good portfolio increases with increases in both $X$ and $Z$ so long as $\mu<1$, which was also a necessary condition for $d \mathbf{n}_{j}$ to respond positively to $d z_{j}$.

\section{A.3 Portfolio allocations}

We now develop expressions for portfolio allocations in terms of the complex securities in the symmetric case under study. That is: we use the expressions derived above to simplify the coefficients $\vartheta_{j}^{n}, \vartheta_{j}^{N}, \vartheta_{j}$ which represent expenditures on each of the three complex securities in the portfolio that supports the optimum. Beginning with the coefficient on the domestic nontraded good, we have

$$
\begin{gathered}
\vartheta_{j}^{n}=\frac{\varepsilon_{j}^{z}}{\Lambda_{j}^{z}}=1+\frac{\alpha_{j}^{z}}{\Lambda_{j}^{z}} \\
\vartheta_{j}^{n}=1+\left(\frac{x}{p z}\right) \frac{\eta^{z}}{\mu \eta^{z}+(1-\mu)} .
\end{gathered}
$$

Next, the coefficient on the world nontraded good portfolio is:

$$
\begin{gathered}
\vartheta_{j}^{N}=\frac{\varepsilon_{j}^{Z}}{\Lambda_{N}^{Z}}-\frac{\varepsilon_{j}^{z}}{\Lambda_{j}^{z}} \frac{\Lambda_{j}^{Z}}{\Lambda_{N}^{Z}} \\
=\frac{-\left(\eta^{Z} x+\mu(p z) \eta^{Z}\right)}{(p z)(1-\mu)}-\vartheta_{j}^{n} \frac{-\mu(p z) \eta^{Z}}{(p z)(1-\mu)} \\
=\frac{\eta^{Z}}{1-\mu}\left[\frac{-x}{p z}+\frac{x}{p z} \frac{\eta^{Z}}{\mu \eta^{Z}+(1-\mu)} \mu\right] \\
=\left(\frac{\eta^{Z}}{1-\mu}\right)\left(\frac{x}{p z}\right)\left[-1+\frac{\eta^{Z} \mu}{\mu \eta^{Z}+(1-\mu)}\right]
\end{gathered}
$$




$$
=\left(\frac{-x}{p z}\right)\left[\frac{\eta^{Z}}{\mu \eta^{Z}+(1-\mu)}\right]=-\left(\vartheta_{j}^{n}-1\right) .
$$

Finally, the coefficient on the traded good portfolio simplifies to:

$$
\vartheta_{j}^{T}=\varepsilon_{j}^{X}-\Lambda_{N}^{X} \vartheta_{j}^{N}-\Lambda_{j}^{X} \vartheta_{j}^{n}=\left(1+\mu \frac{p z}{x}\right)-\left(\mu \frac{p z}{x}\right) \vartheta_{j}^{N}-\left(\mu \frac{p z}{x}\right) \vartheta_{j}^{n}
$$

which after substitution of $\vartheta_{j}^{N}$ and $\vartheta_{j}^{n}$ yields:

$$
\vartheta_{i}^{T}=1
$$




\section{References}

[1] Arrow. Kenneth J. (1964) "The role of securities in the optimal allocation of risk-bearing," Review of Economic Studies 31 (April 1964), 91-96.

[2] Baxter, Marianne and Urban J. Jermann (1993) "The international diversification puzzle is worse than you think," Rochester Center for Economic Research, Working Paper \#350.

[3] Black, F., Business Cycles and Equilibrium, NY: Basil-Blackwell, 1987.

[4] Branson, William and Dale Henderson (1985) "The specification and influence of asset markets," in: Handbook of International Economics II (R. Jones and P. Kenen, eds.) Amsterdam: North-Holland, 1995.

[5] Debreu, Gerard (1959) Theory of Value. New Haven, Conn.: Yale University Press, 1959.

[6] Eldor, Rafael, Pines, David and Schwartz, Abba (1988) "Home asset preference and productivity shocks," Journal of International Economics 25, 165-176.

[7] Frisch, Ragnar (1932) New methods of measuring marginal utility, Tübingen: J.C.B. Mohr, 1932.

[8] Ghosh, A. R. and Pesenti, Paolo (1993) "International diversification, nontradable incomes and consumption growth: Some puzzles and interpretations," unpublished paper, Princeton University.

[9] Jones, Ronald (1965) "The structure of simple general equilibrium models," Journal of Political Economy 73 (1965), 557-572.

[10] Krugman, Paul (1981) "Consumption preferences, asset demands, and distributional effects," Working Paper \#651, National Bureau of Economic Research, Cambridge, MA.

[11] Lewis, Karen K. (1994) "On the welfare costs of the lack of international risktaking," manuscript, Wharton School, University of Pennsylvania, May 1994.

[12] Pesenti, Paolo and van Wincoop, Eric (1994) "International portfolio diversification and non-traded goods," unpublished manuscript, Boston University.

[13] Stockman, Alan C. and Dellas, Harris (1989) "International portfolio diversification and exchange rate variability, "Journal of International Economics 26, 271-290.

[14] Stulz, Rene (1983) "The demand for foreign bonds," Journal of International Economics 15 (November 1983), 225-238. 
[15] Tesar, Linda L. (1993) "International risk sharing and non-traded goods," Journal of International Economics 35, 69-89.

[16] -_____ (1994) "Evaluating the gains from international risksharing," manuscript, University of California, March 1994.

[17] Tesar, Linda L. and Werner, Ingrid M. (1992) "Home bias and the globalization of securities markets," NBER Working Paper 4218. 
Figure 1

Portfolio share of domestic nontraded-good equities

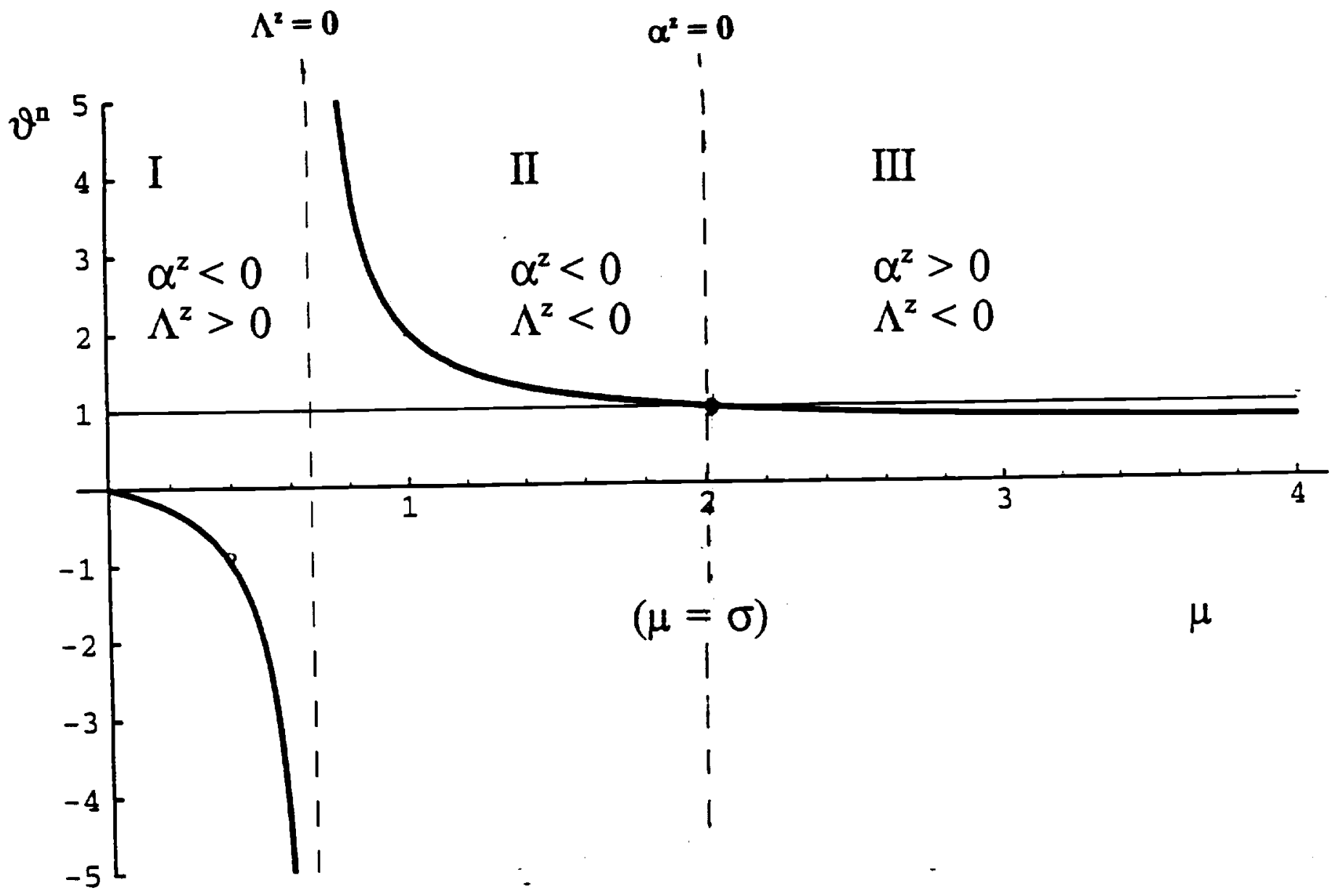

$\vartheta^{n} \quad=$ portfolio share of the domestic nontraded-good equities

$\alpha^{3} \quad=$ sensitivity of $x$ with respect to $z$ (same sign as $(\mu-\sigma)$ )

$\Lambda^{z} \quad=$ sensitivity of the return of nontraded-good equity to $z$

$\mu \quad=$ inverse of the elasticity of substitution

$\sigma \quad \Rightarrow$ risk aversion $(\sigma=2)$

$s_{x} s_{z}=$ consumption value shares $\left(s_{x}=s_{z}=0.5\right)$ 